\title{
O TRABALHO COLABORATIVO PARA A INCLUSÃO ESCOLAR: ARTICULANDO O ENSINO COMUM E ESPECIAL
}

Naiara Chierici da Rocha, Elisa Tomoe Moriya Schlünzen, Danielle Aparecida do Nascimento dos Santos

Universidade Estadual Paulista - FCT/UNESP, Mestrado em Educação, Presidente Prudente, SP. Agência de fomento: CAPES. E-mail: naiaracr27@gmail.com

\section{RESUMO}

O presente trabalho trata-se de uma pesquisa de Mestrado em andamento, que visa analisar a articulação do trabalho do professor de Matemática da sala comum com o professor que atua na Educação Especial na área da Deficiência Intelectual (DI), a partir da proposta de uma prática pedagógica baseada no desenvolvimento de projetos em uma abordagem Construcionista Contextualizada e Significativa (CCS). A pesquisa está em fase de análise de dados coletados em uma escola pública da rede estadual de ensino localizada na cidade de Presidente Prudente/São Paulo, Brasil. A coleta de dados se deu em duas fases procedimentais: Observação e entrevistas, e Intervenção por meio de Trabalho com Projetos. A partir dessas fases procedimentais será possível interpretar e analisar os dados obtidos a fim de contribuir nos princípios norteadores para um ensino colaborativo.

Palavras-chave: Inclusão, Trabalho com Projetos, Ensino Colaborativo.

\section{THE COLLABORATIVE WORK FOR SCHOOL INCLUSION: ARTICULATING COMMON AND SPECIAL EDUCATION}

\begin{abstract}
This paper deals is a Master's ongoing research, which aims to analyze the articulation of the common room of the Mathematics teacher work with the teacher engaged in Special Education in the area of Intellectual Disability (DI) from the draft a pedagogical practice based on the development of projects in a constructionist Contextual and Meaningful approach (CCS). The research is in data analysis phase collected in a public school in the state schools in the city of Presidente Prudente / São Paulo, Brazil. The data collection was carried out in two procedural stages: observation and interviews, and Intervention through Working with Projects. From these procedural stages it will be possible to interpret and analyze the data obtained in order to help the guiding principles for collaborative learning.
\end{abstract}

Keywords: inclusion, work with projects, collaborative learning 


\section{INTRODUÇÃO}

A inclusão escolar de estudantes Público-Alvo da Educação Especial (PAEE) na rede regular de ensino tem sido marcada pela efetivação de políticas públicas que versam sobre a Educação Especial em uma perspectiva de educação inclusiva. Esse marco, é caracterizado pelos serviços e profissionais da Educação Especial prestados para o ensino regular, a partir do Atendimento Educacional Especializado (AEE) na esfera da política nacional, e o Atendimento Pedagógico Especializado (APE) na esfera da política estadual do estado de São Paulo que ocorre nas Salas de Recursos (SR).

Nessa perspectiva, é necessário pensar como pode ser melhor desenvolvido esses atendimentos especializados na escola regular. De acordo com Schlünzen (2000), a abordagem CCS consiste em criar situações que permitam ao estudante resolver problemas reais e aprender com o uso e com a experiência, com os conceitos envolvidos no problema que está sendo proposto. Despertando o interesse do estudante e o motivando a explorar, pesquisar, descrever, refletir e a depurar as ideias.

A partir dessa abordagem, acredita-se na metodologia de Projetos, pois essa proposta é de que os professores devem incentivar e proporcionar situações para que os estudantes se expressem de tal forma que, como afirma Hernardez e Ventura (1998), se torne possível transformar as informações pré-existentes (conhecimento cotidiano) para o que a escola possa auxiliá-lo a sistematizar e formalizar transformando em conhecimento científico.

Desse modo, a partir de Friend e Cook (1990), compreende-se que a colaboração a qual se pretende articular às concepções da abordagem CCS e do trabalho com Projetos é a de interação entre os professores e gestão escolar, que juntos possam compartilhar e se engajar em tomadas de decisão, trabalhando e planejando com um objetivo em comum. Assim, a partir da abordagem CCS e do Trabalho com Projetos podem caracterizar um modelo de educação pautado na ação do aluno e considerar a sua real experiência e envolvimento com a vida e com o mundo, despertando a curiosidade e o prazer em relação ao saber.

A partir dessas perspectivas, o objetivo dessa pesquisa foi o de Analisar de que forma pode se dar a articulação do trabalho do professor de Matemática da sala comum com o professor que atua na Educação Especial na área de Deficiência Intelectual, a partir da proposta de uma prática pedagógica baseada no desenvolvimento de projetos em uma abordagem CCS. 


\section{METODOLOGIA}

Essa pesquisa é de caráter qualitativo, pois apresenta como característica principal a escolha de um ambiente natural (escola pública/SR) como fonte de dados, possibilitando um envolvimento direto entre o pesquisador e os sujeitos da pesquisa em um trabalho de participação e cooperação. Assim, Bogdan e Biklen (1994) discutem o conceito de pesquisa qualitativa e classifica uma das propriedades básica como: 0 ambiente natural como fonte de dados, o pesquisador como principal instrumento, dados descritivos, preocupa-se com o processo, e a análise passa por um processo indutivo.

\section{Universo da pesquisa}

Esta pesquisa foi desenvolvida em uma escola da rede estadual de ensino regular, e os participantes foram duas professoras ${ }^{1}$, uma que atua na Educação Especial na especialidade de Deficiência Intelectual, e uma professora que atua na sala comum na especialidade de Matemática. A sala de aula comum escolhida foi uma sala de sexto ano do Ensino Fundamental, a qual tinha duas estudantes com DI incluídas e que frequentavam a SR no contra turno da sala de aula comum. Dessa forma, foram definidas três fases procedimentais. Vale ressaltar que dessas fases duas já foram executadas, sendo assim, essa pesquisa encontra-se em fase de análise e validação dos dados coletados.

\section{Fases procedimentais:}

\section{1ạ fase: identificação das características do contexto}

Nesta fase, existiu a perspectiva de compreender a atuação dos participantes (práticas pedagógicas) em seu contexto (na sala comum e na SR). Sendo assim para o desenvolvimento do primeiro procedimento, foi realizada uma observação prévia acompanhada de uma entrevista semiestruturada com os professores participantes, foram os primeiros instrumentos de coleta de dados utilizado a fim de identificar como é desenvolvido o processo de ensino da Matemática e as estratégias pedagógicas utilizadas.

Essa entrevista foi pensada a partir de blocos temáticos contendo-os: Informações gerais e profissionais, Trabalho Pedagógico tanto na SR quanto na Sala comum, Trabalho/Ensino Colaborativo, Inclusão e Trabalho com Projetos e Gestão Democrática e Participativa. Por uma sugestão do comitê de ética, o roteiro foi formulado pensando no bem-estar dos sujeitos

\footnotetext{
${ }^{1}$ Destaca-se que essa pesquisa foi aprovada pelo Comitê de Ética número: 36689414.5.0000.5402 
entrevistados, sendo assim, optou-se por realizar as entrevistas divididas em 2 momentos separados por blocos temáticos, pois dessa forma, os sujeitos entrevistados não ficarão cansados ou se sentindo pressionados para responder qualquer pergunta. As entrevistas foram gravadas e posteriormente transcritas para análise, justificando a dando subsídios para as coletas das fases seguintes, bem como para a prática pedagógica dos sujeitos da pesquisa.

O segundo procedimento refere-se a observações das atividades desenvolvidas na SR e na sala comum tendo em vista o processo de ensino e aprendizagem relacionados aos conteúdos matemáticos. A observação foi um importante instrumento de coleta de dados, uma vez que para Lüdke e Andre (1986) é usada como o principal método da investigação e possibilita um contato pessoal e estreito do pesquisador com o fenômeno pesquisado, e o observador pode recorrer aos conhecimentos e experiências particulares no desenvolvimento do estudo.

A observação ocorreu no interior das salas, a fim de coletar nuances que possam contribuir para o objetivo da pesquisa, bem como para a melhoria do ambiente escolar e trabalho pedagógico. A observação, além de permitir ao pesquisador conhecer o contexto da pesquisa, também visou coletar dados para a análise colaborativa com os professores participantes. Sendo assim, as observações, foram registradas pela pesquisadora, em um diário de campo.

\section{2a Fase: Desenvolvimento do processo de reflexão, intervenção por meio de Trabalho com} Projetos: A construção do projeto: Gestão Ambiental: Eu no ambiente escolar.

Essa fase teve por objetivo propor ações colaborativas entre as professoras envolvidas. Para isso, foram organizados e desenvolvidos encontros como o terceiro procedimento, que teve como instrumento de coleta de dados o diálogo e o diário de campo com os professores participantes para analisar os registros realizados e identificar possíveis modificações a serem implementadas ou aperfeiçoadas, bem como a análise dos resultados obtidos.

Os registros da primeira etapa foram analisados colaborativamente por meio de um processo reflexivo buscando estimular nos participantes a reflexão e a problematização da sua atuação articulados aos referenciais estudados e concretizar a segunda fase da pesquisa, por meio de um Projeto construído colaborativamente.

Esse projeto foi desenvolvido de forma colaborativa, o qual foi construído colaborativamente a partir da realidade, necessidades e especificidades de cada estudante da sala de aula comum. O projeto foi intitulado: Gestão Ambiental: Eu no ambiente escolar, essa escolha deu-se dado a temática escolhida para o projeto, o problema a ser resolvido, bem como as áreas do conhecimento envolvidas no currículo no momento da construção e desenvolvimento do 
projeto. Sendo assim, foram realizadas três etapas do projeto, sendo elas: 1a Etapa- Pesquisa na sala de informática; 2a Etapa- Pesquisa de Campo: Coleta de dados no ambiente escolar; 3a EtapaOrganização dos dados e construção de tabelas.

\section{3a Fase: Definição de princípios, por meio de interpretações dos dados obtidos para categorias} de análise.

A partir dessas duas fases procedimentais já ocorridas em campo, está sendo sistematizada a terceira fase da pesquisa, a qual consiste na definição de princípios, por meio de interpretações dos dados obtidos para categorias de análise. Essa fase resulta em analisar e definir princípios a partir dos resultados obtidos nas fases anteriores, para nortearem a construção colaborativa de estratégias pedagógicas de Matemática para o ensino regular organizadas em uma abordagem CCS.

A análise dos dados coletados durante todo o processo em que a parte empírica da pesquisa se desenvolveu, será por meio de categorias de análise, que serão criadas a partir da leitura sistemática e sucessiva de todos os dados coletados a fim de encontrar elementos que possam ser agrupados, sem perder de vista o que se pretende de modo geral. A categorização permite ao pesquisador "analisar não apenas o que está explícito, mas que "procure ir mais a fundo, desvelando mensagens implícitas, dimensões contraditórias e temas sistematicamente 'silenciados'”. (LÜDKE; ANDRÉ, 1986, p. 48). Assim, espera-se que a partir da análise de todo o processo, sejam encontrados dados que contribuam para nortear o trabalho pedagógico dos professores envolvidos, tendo em vista a construção de estratégias pedagógicas para a articulação e trabalho colaborativo entre os professores (especialista da Educação Especial e o da sala comum).

\section{RESULTADOS}

A coleta de dados foi realizada no período de 5 meses, sendo estes referentes ao segundo semestre de 2014. Sendo assim, considera-se que o convívio no ambiente escolar durante a pesquisa de campo foi suficiente para a efetiva coleta de dados das duas fases procedimentais destacadas anteriormente, uma vez que, foi possível criar um espaço de confiança entre a pesquisadora e os sujeitos participantes na pesquisa.

Em relação ao primeiro procedimento (entrevista semiestruturada), foi possível analisar diferentes concepções entre inclusão e práticas pedagógicas inclusivas entre as referidas professoras. O distanciamento dessas concepções refere-se à formação específica de ambas, 
enquanto uma possui formação na Educação Especial e pós-graduação nas áreas de educação inclusiva, a outra possui licenciatura em Matemática, e nunca realizou formação na área da educação inclusiva. Esse fato, implica nas práticas pedagógicas para os estudantes PAEE.

Junto as entrevistas e observação em campo, foi possível constatar que não havia práticas colaborativas, desde do planejamento à construção de práticas e estratégias de ensino que contemplasse a articulação da sala comum e Educação Especial para as estudantes com Deficiência Intelectual (DI) observadas. Mas, junto ao esse fato, percebeu-se que as próprias condições de trabalhos das professoras envolvidas dificultavam um processo de ensino colaborativo, uma vez, que havia sobrecarga de aulas, e os horários eram distintos fazendo com que as professoras se encontrassem apenas durante a Aula de Trabalho Pedagógico Coletivo (ATPC).

Dessa forma, durante a coleta de dados, foi proposto um intenso trabalho de acompanhamento e reflexão junto as professoras participantes da pesquisa, para a compreensão da proposta de um ensino colaborativo, possibilidades e desafios, até a concretização de um Projeto construído junto com as professoras, visando um ensino contextualizado e significativo para todos. O projeto "Gestão Ambiental: Eu no ambiente escolar, envolveu atividades e articulação com todos os setores da escola, demonstrando que é possível trabalhar de forma colaborativa, a partir da proposta de Projetos em uma abordagem CCS. Vale ressaltar que no projeto foram considerados atividades do currículo de Matemática, Ciências e Geografia, contemplando um mesmo currículo para todos os estudantes, considerando as especificidades e habilidades de cada um.

Em relação aos resultados do projeto, em termos de aprendizagem, pode-se considerar que houve aprendizagens, houve, interação, compartilhamento e construções significativas de conhecimento, isso foi notório a partir dos resultados construídos em cada etapa do projeto, desde de atitudes à sistematização de conceitos. Mas, não se pode dizer que com esse projeto houve mudanças de conduta, tanto na postura dos estudantes quanto nas práticas das professoras, no entanto, pode se refletir que esse foi um passo de investigação que tem possibilitado apresentar fragilidades existentes na escola, mas, ao mesmo tempo, potencialidades de que a mudança é possível.

Assim, todos os estudantes puderem se desenvolver juntos, cada um à sua maneira e considerando suas habilidades e potencialidades na sala de aula comum, conforme ilustra a Figura 1. 


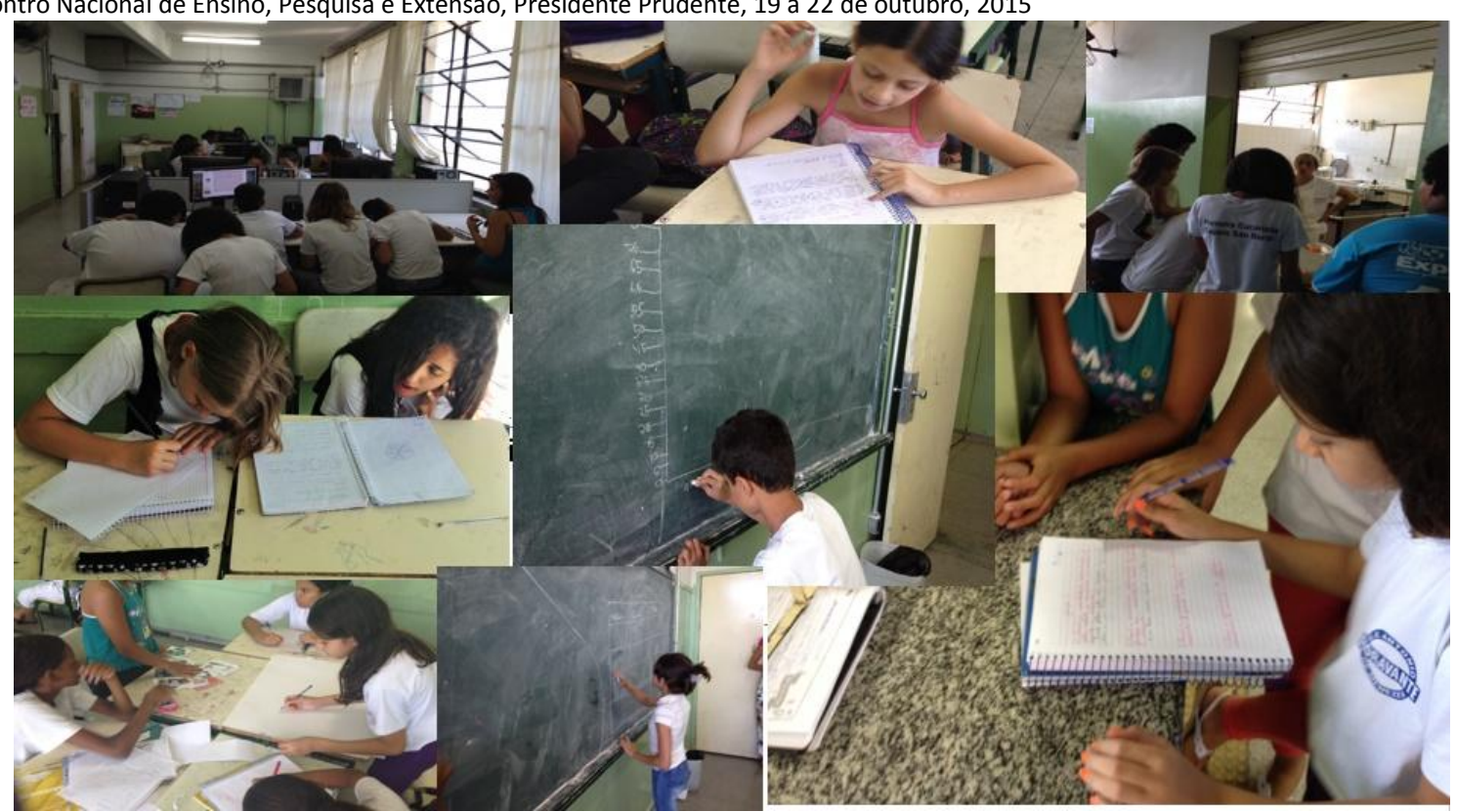

Figura 1. Atividades desenvolvidas durante as etapas do projeto Gestão Ambiental: Eu no Ambiente Escolar.

\section{DISCUSSÃO}

A partir do que foi coletado e analisado até o presente momento, é possível considerar acerca da realidade observada que: é necessário se efetivar políticas públicas que considerem os desafios presentes em contextos reais de ambientes escolares, desde das situações de ensino e aprendizagem à condições de trabalho dos professores; é fundamental compreender o conceito de educação inclusiva e se pautar nos princípios de ensino colaborativo para que a Educação Especial caminhe junto com o ensino regular; é considerável propor o elo mediador entre a Educação Especial e classe comum, mas desde que esse profissional tenha a clareza de suas atribuições e que não seja mais um agente de ensino que trabalhe de forma desarticulada; é imprescindível que se busque metodologias de ensino centradas em um novo fazer pedagógico, que considere as diferenças. Não se pode mais robotizar a educação.

Concorda-se que há um longo percurso a ser conquistado, há desafios a serem superados, problemas a serem resolvidos, mas também reconhece-se que há mudanças acontecendo, e que a partir dessa pesquisa de campo, é possível desenvolver propostas de ensino com a articulação entre o ensino regular e Educação Especial, mas para isso, é necessário repensar as estruturas da escola, os papeis de cada agente escolar, a valorização docente, formação em serviço que contemple de forma mais consistente os princípios da educação inclusiva. Por isso, acredita-se que o ensino colaborativo por peio de Trabalho com Projetos em uma abordagem CCS podem auxiliar em um processo de inclusão escolar. 
Acredita-se no desenvolvimento de estratégias e práticas de ensino em parcerias, colaboração e cooperação, articulando os serviços da Educação Especial com a escola regular, baseadas na pedagogia de projetos se torna uma possibilidade de um ensino inclusivo, seja para a Matemática, assim como, para todas as áreas do conhecimento. Nesse sentido, acredita-se em metodologias ativas que proporcione práticas de ensino que considere as habilidades dos estudantes ao invés das dificuldades, dado que o ensino é coletivo, mas a aprendizagem é individual e possui um sentido e significado diferente para cada um.

\section{CONCLUSÃO}

A pesquisa está em fase de análise dos dados para escrita final da dissertação de Mestrado. Os registros do campo foram transcritos de modo reflexivo, e já aponta nuances da realidade do contexto investigado. Nota-se que as barreiras impostas do sistema de ensino impedem que sejam desenvolvidas práticas colaborativas no ambiente escolar, e com isso, percebe-se uma fragmentação nas práticas pedagógicas, dificultando um planejamento e maior dedicação docente em relação a cada sala de aula, e mais especificamente para os estudantes com DI.

Ao indicar as categorias de análise das entrevistas, percebe-se um distanciamento entre a professora da sala comum e a professora especializada em DI, no que tange à práticas inclusivas, concepção de inclusão e formação necessária para inclusão escolar. Assim, já fica evidente, a necessidade de orientação e formação para que o professor da sala de aula comum possa trabalhar de forma consistente e eficiente no ambiente escolar, assim como a valorização profissional que esses profissionais necessitam.

No decorrer da intervenção a partir da Metodologia de Projetos, conclui-se que é possível desenvolver um trabalho em parceria, que envolva o contexto rela dos estudantes, proporcionando a construção de uma aprendizagem significativa. Porém, é necessário expandir para todos os profissionais da escola práticas como essa, para que as atividades escolares sejam todas considerando e valorizando as diferenças presente no ambiente escolar.

\section{REFERÊNCIAS}

BOGDAN, R.; BIKLEN, S. Investigação qualitativa em educação: uma introdução à teoria e aos métodos. Porto: Porto editora, 1994. 336 p.

HERNÁNDEZ, F; VENTURA, M. A Organização do currículo por projetos de trabalho. Porto Alegre: Artmed, 1998.

LÜDKE, M; ANDRÉ, M. Pesquisa em Educação: Abordagens qualitativas. São Paulo: EPU, 1986. 
SCHLÜNZEN, E. T. M. Mudanças nas Práticas Pedagógicas do Professor: criando um ambiente construcionista contextualizado e significativo para crianças com necessidades especiais físicas. São Paulo, 2000. Tese (Doutorado em Educação: Currículo). Pontifícia Universidade Católica de São Paulo (PUC_SP).

FRIEND, M.; COOK, L. Collaboration as a predictor for success in school reform. Journal of Educational and Psychological Consultation, v.1, n.1, p.69-86, 1990. http://dx.doi.org/10.1207/s1532768xjepc0101 4 